\title{
OPEN Publisher Correction: Multi-decadal
} variability and linkage to solar forcing in the Western Mediterranean during the last 1000 years

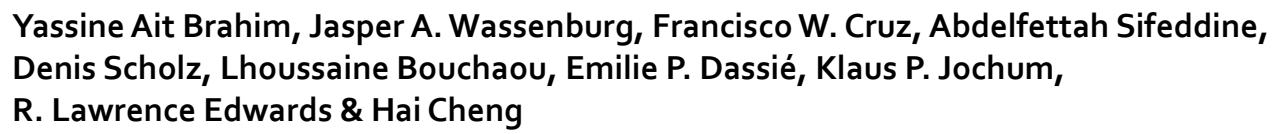

Correction to: Scientific Reports https://doi.org/10.1038/s41598-018-35498-x, published online 28 November 2018.

The original version of this Article contained errors.

The author R. Lawrence Edwards was omitted from the Supplementary Material author list and the Author Contributions Statement. The Author Contributions statement now reads:

"Y.A.B. and J.A.W. prepared the manuscript. Y.A.B. and J.A.W. carried out $\delta 18 \mathrm{O}$ analyses, Th/U dating and XRD analyses. F.W.C., H.C., D.S., R.L.E., and K.P.J. provided lab support. A.S., L.B., J.A.W., F.W.C and H.C. carried out the fieldwork. H.C. directed the project. E.P.D. and all authors provided comments on the manuscript and assisted with discussions."

Additionally, the following affiliation was omitted from the Supplementary Information file:

“Department of Earth Sciences, University of Minnesota, Minneapolis, MN 55455, USA.”

Furthermore, the Data Availability Statement has been updated from:

"After acceptance of the manuscript, the data produced here will be published in a public database such as NOAA or PANGAEA."

to:

"The data presented in this research article can be downloaded from the NOAA paleoclimate database https:// www.ncdc.noaa.gov/paleo-search/study/25970)”.

In addition, Yassine Ait Brahim was omitted as being a corresponding author. Correspondence and request for materials can also be addressed to aitbrahim@xjtu.edu.cn. 
Lastly, in the original HTML version of this Article, R. Lawrence Edwards was incorrectly affiliated with 'Climate Geochemistry Department, Max Planck Institute for Chemistry, Mainz, Germany'. The correct affiliation is listed below:

“Department of Earth Sciences, University of Minnesota, Minneapolis, MN 55455, USA.”

These errors have been corrected in the HTML and PDF versions of the Article, as well as in the Supplementary Material.

(c) (i) Open Access This article is licensed under a Creative Commons Attribution 4.0 International License, which permits use, sharing, adaptation, distribution and reproduction in any medium or format, as long as you give appropriate credit to the original author(s) and the source, provide a link to the Creative Commons license, and indicate if changes were made. The images or other third party material in this article are included in the article's Creative Commons license, unless indicated otherwise in a credit line to the material. If material is not included in the article's Creative Commons license and your intended use is not permitted by statutory regulation or exceeds the permitted use, you will need to obtain permission directly from the copyright holder. To view a copy of this license, visit http://creativecommons.org/licenses/by/4.0/.

(C) The Author(s) 2020 